\title{
A General Platform for Remarkably Thermoresponsive Fluorescent Polymers with Memory Function
}

\author{
Guodong Liang, ${ }^{*}{ }^{\dagger}$ Jialong Wu, ${ }^{\dagger}$ Haiyang Gao, ${ }^{\dagger}$ Qing Wu,${ }^{\dagger}$ Jiang Lu, ${ }^{\dagger}$ Fangming
} $\mathrm{Zhu}^{*}{ }^{* \dagger}$ and Ben Zhong Tang ${ }^{*}$

${ }^{\dagger}$ DSAP, PCFM and GDHPPC lab, School of Materials Science and Engineering, School of Chemistry and Chemical Engineering, Sun Yat-sen University, Guangzhou 510275, China

${ }^{\ddagger}$ Department of Chemistry, Institute for Advanced Study, Division of Biomedical Engineering, State Key Laboratory of Molecular, Neuroscience and Institute of Molecular Functional Materials, The Hong Kong University of Science and Technology, Clear Water Bay, Kowloon, Hong Kong, China

\section{Experimental Section}

\section{Materials and Instrumentations}

The initiator of 2-(4-(triphenylvinyl)phenoxy)ethanol (1) has been synthesized in our lab (yield: 42\%). ${ }^{1} \quad$ Tetrahydrofuran $\quad$ (THF) was distilled from sodium benzophenone ketyl immediately prior to use. 4-hydroxybenzophenone, potassium 
carbonate, 2-bromoethanol, benzophenone, $\varepsilon$-caprolactone, stannous octoate and other chemicals were all purchased from Aldrich and used as received without further purification unless otherwise indicated.

${ }^{1} \mathrm{H}$ NMR spectra were measured on a Bruker ARX400 NMR spectrometer using chloroform- $d$ as solvent and tetramethylsilane (TMS) as internal reference. Molecular weight and molecular weight distribution of tetraphenylethene terminated poly( $\varepsilon$-caprolactone) (PCL-TPE) synthesized were determined using gel permeation chromatography (GPC) (Waters Breeze 2417) calibrated with polystyrene standard and with THF as eluent. DSC measurement was carried out using a Perkin-Elmer DSC-7 Instrument under nitrogen atmosphere. Temperature was calibrated with indium prior to the test. Fluorescence (FL) spectra were recorded on a Perkin Elmer LS 55 spectrofluorometer with a temperature controller. To eliminate the effect of thermal history on fluorescence emission, PCL-TPE was subjected to identical thermal treatments prior to fluorescence measurements (held at $120{ }^{\circ} \mathrm{C}$ for $5 \mathrm{~min}$ under $\mathrm{N}_{2}$, cooled to $25^{\circ} \mathrm{C}$ in $10 \mathrm{~min}$, further cooled to $-10^{\circ} \mathrm{C}$ for $20 \mathrm{~min}$, restored to $0^{\circ} \mathrm{C}$ for $\left.10 \mathrm{~min}\right)$. Time-resolved FL spectra and quantum yield of PCL-TPE were measured by using an Edinburgh Instruments spectrometer (FLSP920). Polarizing optical microscopy (POM) images were obtained using an Olympus instrument (BX50) with a hot stage. X-ray Diffraction (XRD) measurements were performed using XRD diffractometer (D-MAX 2200 VPC) equipped with Ni-filtered $\mathrm{Cu} \mathrm{K \alpha}$ radiation, having a wavelength of $0.154 \mathrm{~nm}$. The diffractometer was scanned in $2 \theta$ range of $5^{\circ}-50^{\circ}$ and the scanning rate used was $1.2 \%$ min. 


\section{Synthesis.}

\section{Synthesis of poly(E-caprolactone) terminated with tetraphenylethene (PCL-TPE).}

Poly(E-caprolactone) terminated with tetraphenylethene (PCL-TPE) was synthesized by the ring-opening polymerization of $\varepsilon$-caprolactone using $\mathbf{1}$ as initiator and stannous octoate as catalyst. Briefly, prescript amount of freshly distilled $\varepsilon$-caprolactone, stannous octoate and compound $\mathbf{1}$ were added into ampoules pre-treated with trimethylsilyl chloride. The ampoules were sealed and placed in an oil-bath of $110^{\circ} \mathrm{C}$. The polymerization was allowed to process $12 \mathrm{~h}$. Upon cooling to room temperature, $10 \mathrm{~mL}$ of THF was added. The solution was added dropwise into $200 \mathrm{~mL}$ of cold methanol with stirring. The solid was isolated by filtration, and dried in vacuum at $40{ }^{\circ} \mathrm{C}$ overnight to yield while powders.

Scheme S1. Synthetic Route for Poly( $\varepsilon$-caprolactone) Terminated with Tetraphenylethene (PCL-TPE).

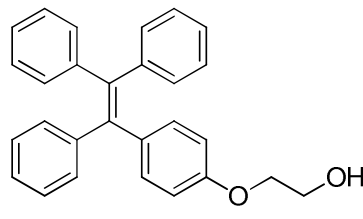

1

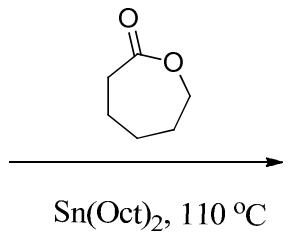

$\operatorname{Sn}(\mathrm{Oct})_{2}, 110^{\circ} \mathrm{C}$

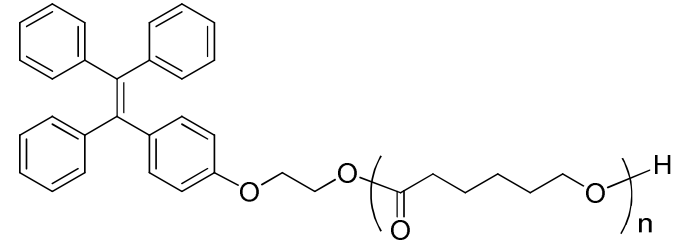

PCL-TPE

PCL4k-TPE: Yield 81\%. ${ }^{1} \mathrm{H}$ NMR (400 MHz, $\mathrm{CDCl}_{3}$ ), $\delta$ (TMS, ppm): 1.37 (m, 65H, $\mathrm{COOCH}_{2} \mathrm{CH}_{2} \mathrm{CH}_{2}$ ), $1.64\left(\mathrm{~d}, 130 \mathrm{H}, \mathrm{COOCH}_{2} \mathrm{CH}_{2} \mathrm{CH}_{2} \mathrm{CH}_{2}\right.$ ), 2.30 (t, 64H, $\mathrm{COCH}_{2}$ ), $3.64\left(\mathrm{t}, 2 \mathrm{H}, \mathrm{CH}_{2} \mathrm{OH}\right), 4.05\left(\mathrm{t}, 63 \mathrm{H}, \mathrm{OCH}_{2}\right), 4.38\left(\mathrm{~s}, 2 \mathrm{H}, \mathrm{OCH}_{2} \mathrm{CH}_{2} \mathrm{O}\right.$ from initiator), 6.6-7.1 (m, 19H, Ar-H from initiator).

PCL8k-TPE: Yield 85\%. ${ }^{1} \mathrm{H}$ NMR (400 MHz, $\mathrm{CDCl}_{3}$ ), $\delta$ (TMS, ppm): 1.37 (m, $134 \mathrm{H}, \mathrm{COOCH}_{2} \mathrm{CH}_{2} \mathrm{CH}_{2}$ ), 1.64 (d, 263H, $\mathrm{COOCH}_{2} \mathrm{CH}_{2} \mathrm{CH}_{2} \mathrm{CH}_{2}$ ), 2.30 (t, $132 \mathrm{H}$, 3 
$\left.\mathrm{COCH}_{2}\right), 3.64\left(\mathrm{t}, 2 \mathrm{H}, \mathrm{CH}_{2} \mathrm{OH}\right), 4.05\left(\mathrm{t}, 130 \mathrm{H}, \mathrm{OCH}_{2}\right), 4.38\left(\mathrm{~s}, 2 \mathrm{H}, \mathrm{OCH}_{2} \mathrm{CH}_{2} \mathrm{O}\right.$ from initiator), 6.6-7.1 (m, 19H, Ar-H from initiator).

PCL12k-TPE: Yield 89\%. ${ }^{1} \mathrm{H}$ NMR (400 MHz, $\mathrm{CDCl}_{3}$ ), $\delta$ (TMS, ppm): 1.37 (m, $\left.198 \mathrm{H}, \mathrm{COOCH}_{2} \mathrm{CH}_{2} \mathrm{CH}_{2}\right), 1.64\left(\mathrm{~d}, 402 \mathrm{H}, \mathrm{COOCH}_{2} \mathrm{CH}_{2} \mathrm{CH}_{2} \mathrm{CH}_{2}\right), 2.30$ (t, $200 \mathrm{H}$, $\left.\mathrm{COCH}_{2}\right), 3.64\left(\mathrm{t}, 2 \mathrm{H}, \mathrm{CH}_{2} \mathrm{OH}\right), 4.05\left(\mathrm{t}, 2 \mathrm{O} 2 \mathrm{H}, \mathrm{OCH}_{2}\right), 4.38\left(\mathrm{~s}, 2 \mathrm{H}, \mathrm{OCH}_{2} \mathrm{CH}_{2} \mathrm{O}\right.$ from initiator), 6.6-7.1 (m, 19H, Ar-H from initiator).

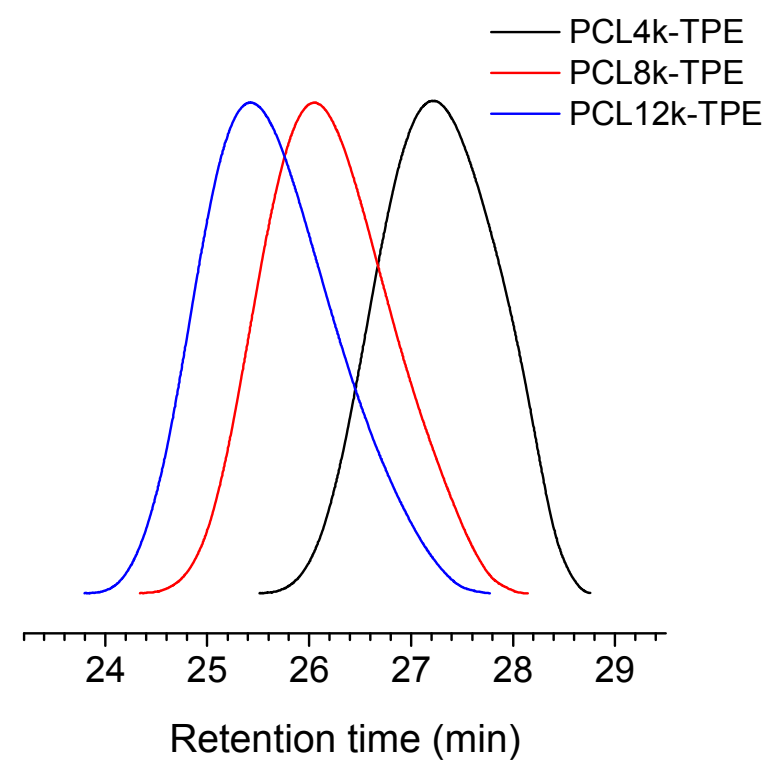

Figure S1. GPC curves of PCL-TPE synthesized using THF as eluent. 

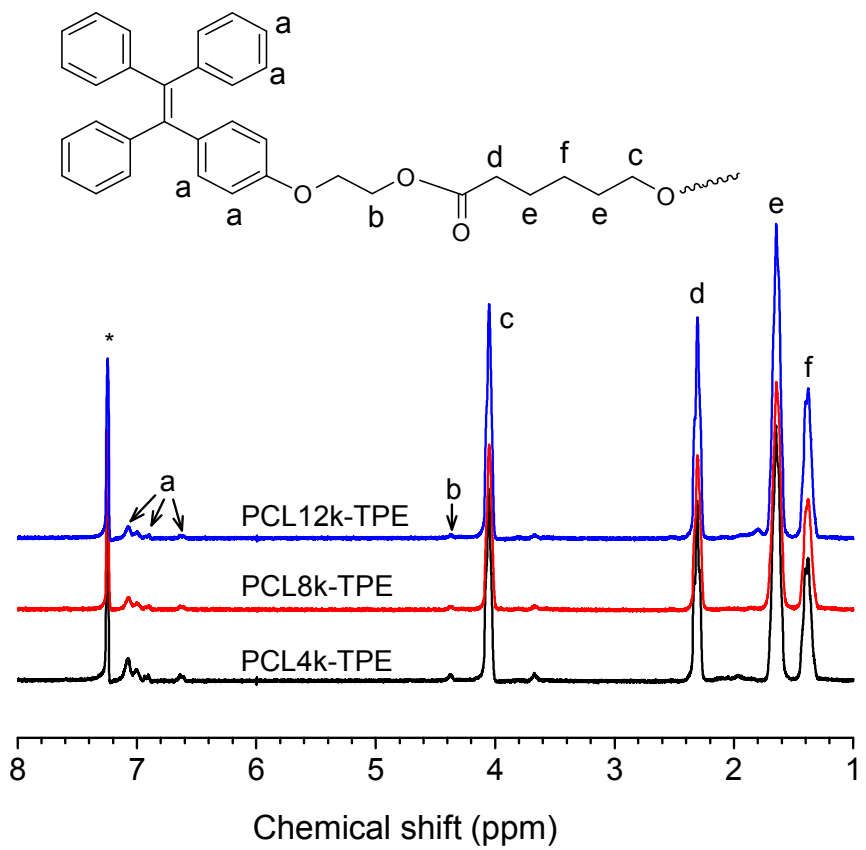

Figure S2. ${ }^{1} \mathrm{H}$ NMR spectra of PCL-TPE in $\mathrm{CDCl}_{3}$. The solvent peak was marked with an asterisk.

Table S1. Molecular Weight and Molecular Weight Distribution of PCL-TPE.

\begin{tabular}{|c|c|c|c|c|c|}
\hline entry & $\begin{array}{l}{ }^{\mathrm{a}} M_{\mathrm{n}} \\
\left(10^{3} \mathrm{~g} / \mathrm{mol}\right)\end{array}$ & $\begin{array}{l}{ }^{\mathrm{b}} M_{\mathrm{n}} \\
\left(10^{3} \mathrm{~g} / \mathrm{mol}\right)\end{array}$ & ${ }^{c} \mathrm{PDI}$ & ${ }^{\mathrm{d}} \mathrm{DP}$ & $\begin{array}{l}{ }^{\mathrm{e}} w \\
(\%)\end{array}$ \\
\hline PCL4k-TPE & 4.0 & 4.8 & 1.21 & 32 & 8.2 \\
\hline PCL8k-TPE & 7.9 & 8.6 & 1.25 & 66 & 4.2 \\
\hline PCL12k-TPE & 11.7 & 12.2 & 1.25 & 100 & 2.8 \\
\hline
\end{tabular}

${ }^{\mathrm{a}} M_{\mathrm{n}}$ denoted number average molecular weight, determined by ${ }^{1} \mathrm{H}$ NMR using $M_{\mathrm{n}}=392+114 \mathrm{DP} .{ }^{\mathrm{b}, \mathrm{c}}$ Determined by GPC calibrated using polystyrene standard. ${ }^{\mathrm{d}} \mathrm{DP}$ denotes the degree of polymerization, determined from ${ }^{1} \mathrm{H}$ NMR spectra of PCL using $\mathrm{DP}=n=9.5 I_{\mathrm{d}} / I_{\mathrm{a}}\left(I_{\mathrm{d}}\right.$ and $I_{\mathrm{a}}$ were the integrate of resonance peak at $2.30 \mathrm{ppm}$ and $6.6-7.1$ ppm in Figure S2, respectively). ${ }^{\mathrm{e}} W$ denoted the weight percentage of TPE in 5 
PCL-TPE, was calculated using $w=\left(M_{\mathrm{TPE}}-1\right) / M_{\mathrm{n}}\left(M_{\mathrm{TPE}}\right.$ and $M_{\mathrm{n}}$ were the molecular weight of TPE and PCL-TPE, respectively).
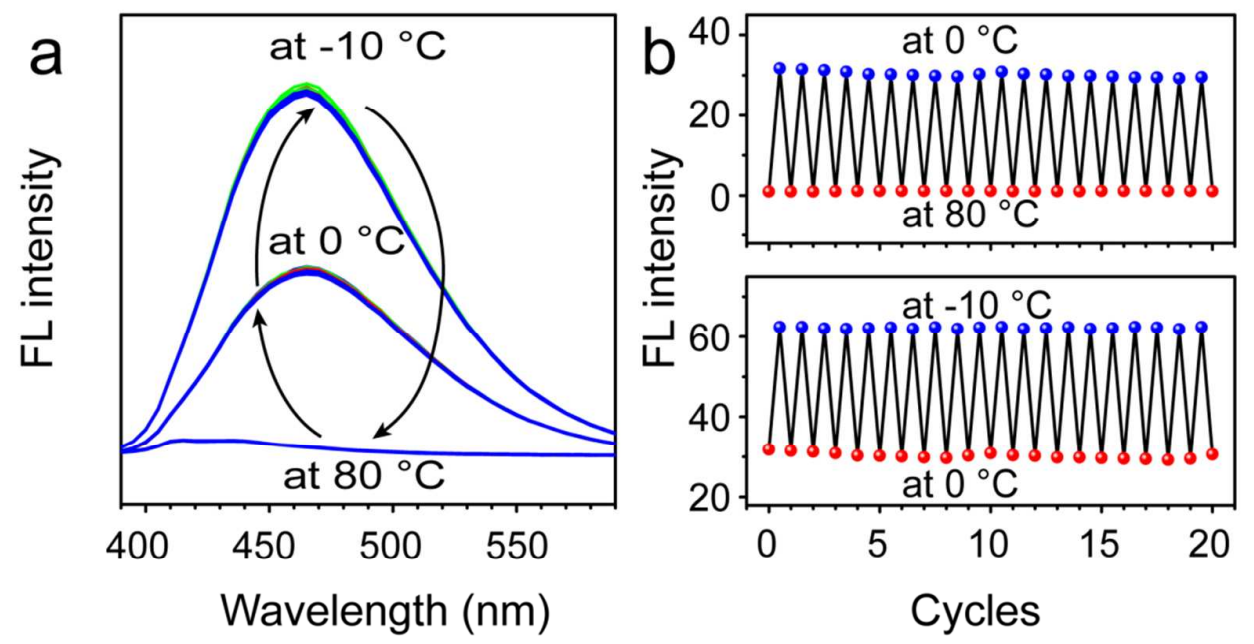

Figure S3. Reversibility of fluorescence of PCL12k-TPE.

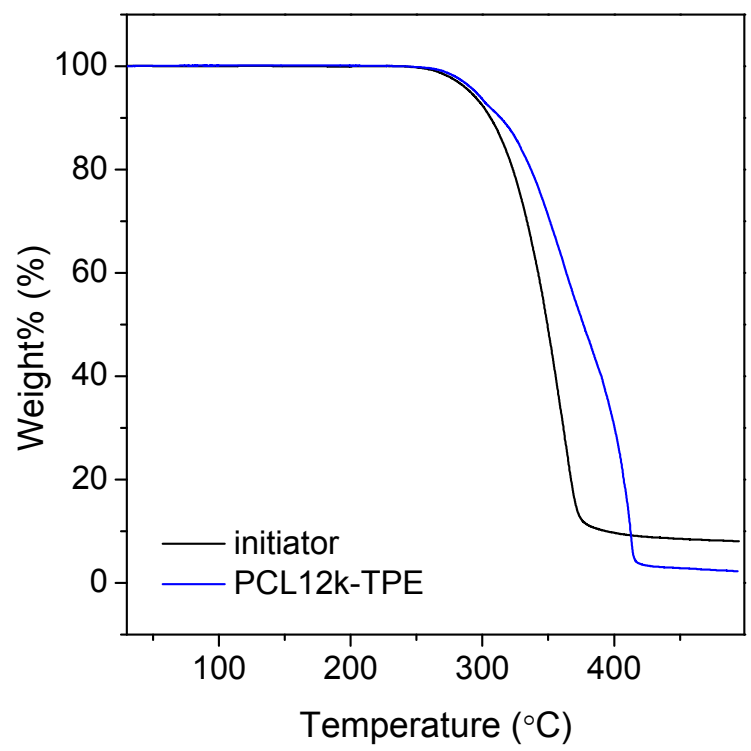

Figure S4. Thermogravimetric analysis (TGA) traces of PCL-TPE and compound 1. Both PCL-TPE and compound 1 were thermally stable up to $250{ }^{\circ} \mathrm{C}$. 

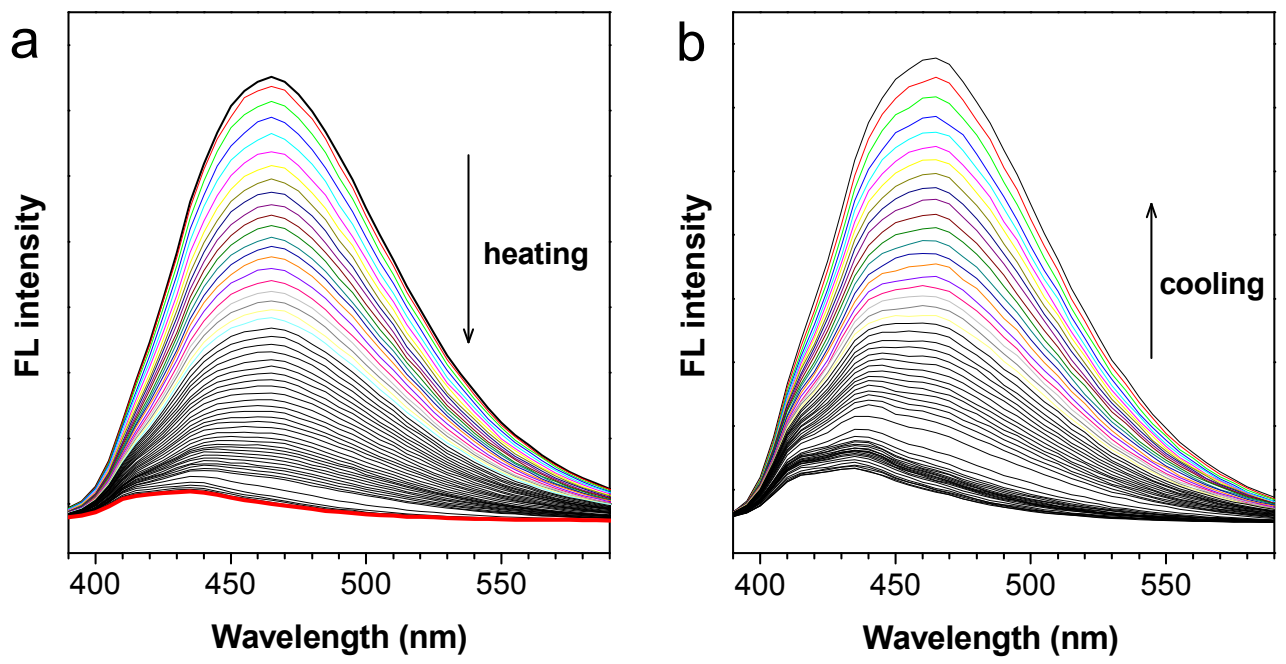

Figure S5. Fluorescence of PCL8k-TPE at various temperatures in heating (a) and cooling (b) scans. Heating and cooling rates were $0.5{ }^{\circ} \mathrm{C} / \mathrm{min}$. Excitation: $350 \mathrm{~nm}$.
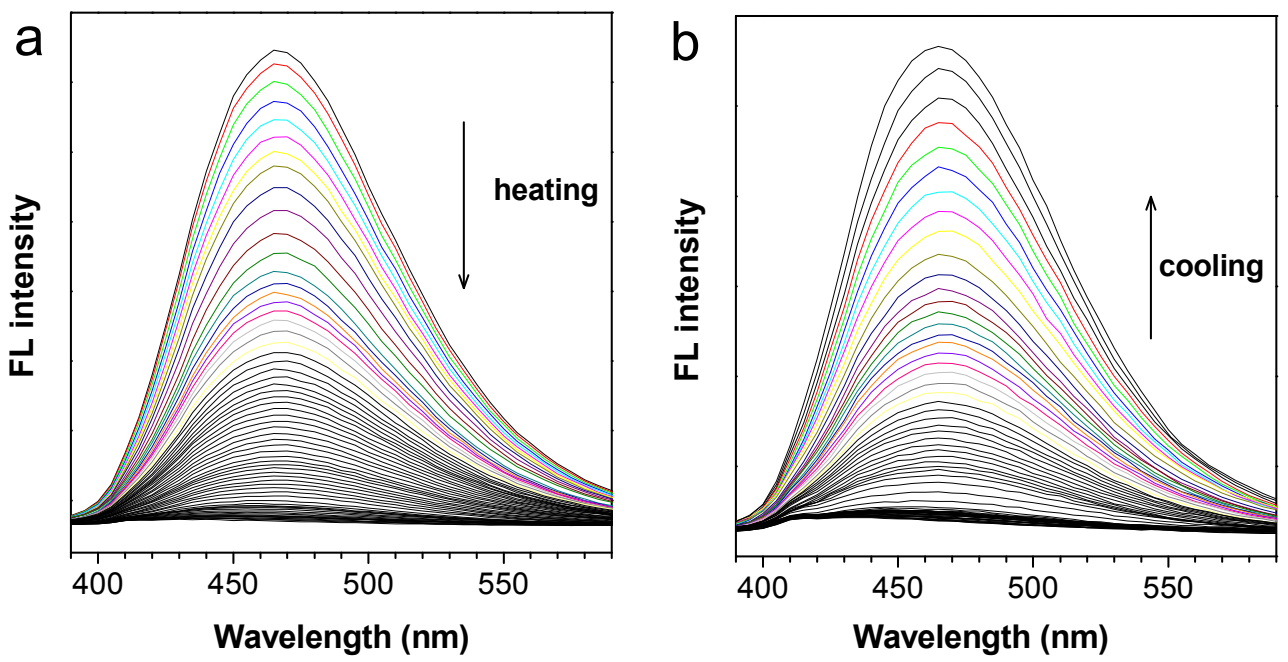

Figure S6. Fluorescence of PCL4k-TPE at various temperatures in heating (a) and cooling (b) scans. Heating and cooling rates were $0.5{ }^{\circ} \mathrm{C} / \mathrm{min}$. Excitation: $350 \mathrm{~nm}$. 


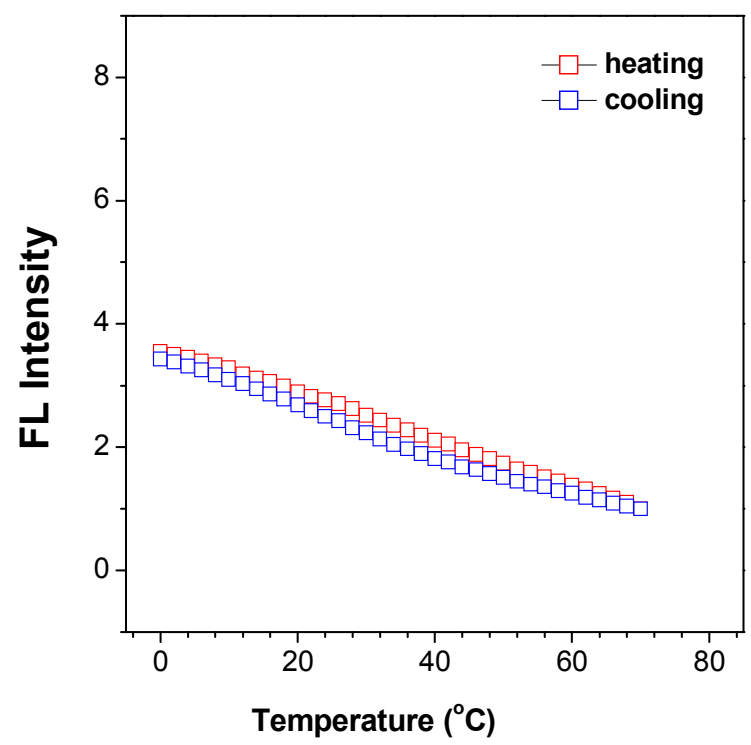

Figure S7. Fluorescence intensity of compound 1 (initiator for polymerization) as a function of temperature in heating and cooling scans. FL intensity of compound $\mathbf{1}$ decreased gradually with increasing temperature from $0{ }^{\circ} \mathrm{C}$ to $70{ }^{\circ} \mathrm{C}$, and almost recovered when temperature returned to $0{ }^{\circ} \mathrm{C}$ again.

\section{Calculation of radiative and non-radiative decay rate constants.}

Fluorescence typically follows first-order kinetics: ${ }^{1}$

$[S]=[S]_{0} e^{-t / \tau}$

[S] is the concentration of exited state molecules at time $t, \quad[\mathrm{~S}]_{0}$ is the initial concentration and $\tau$ is the fluorescence lifetime.

Decay rate $(k)$ is the inverse of lifetime, consisting of radiative and non-radiative decay rate constants:

$k=k_{\mathrm{rad}}+k_{\mathrm{nrad}}$ 
where $k_{\text {rad }}$ is the radiative decay rate constant and $k_{\text {nrad }}$ is the nonradiative decay rate constant. The quantum yield $(Q E)$ is defined as the fraction of emission process in which emission of light is involved:

$$
Q E=\frac{k_{\mathrm{rad}}}{k_{\mathrm{rad}}+k_{\mathrm{nrad}}}
$$

The values of radiative and non-radiative rate constants of PCL-TPE and initiator were tabulated in Table S2.

Quantum yield and lifetime of PCL-TPE decreased with increasing molecular weight of the polymers, due to decreased grafting density $(G)$ and coverage ratio $(C)$ of TPE on PCL-TPE crystal surface. Quantum yield, lifetime, and radiative decay rate of PCL-TPE decreased, while nonradiative decay rate increased after melting, possibly because melting destroyed the perfect crystalline structure of PCL-TPE.

Table S2. Fluorescence Quantum Yield, Lifetime, Radiative Decay Rate and Nonradiative Decay Rate of PCL-TPE before and after Melting.

\begin{tabular}{|c|c|c|c|c|c|c|c|c|}
\hline \multirow{2}{*}{ Sample } & \multicolumn{4}{|c|}{ before melting } & \multicolumn{4}{|c|}{ after melting } \\
\hline & $\begin{array}{l}\Phi \\
(\%)\end{array}$ & $\begin{array}{l}\tau \\
\text { (ns) }\end{array}$ & $\begin{array}{l}k_{\mathrm{rad}} \\
\left(\times 10^{7} \mathrm{~s}^{-1}\right)\end{array}$ & $\begin{array}{l}k_{\text {nrad }}\left(\times 10^{7}\right. \\
\left.\mathrm{s}^{-1}\right)\end{array}$ & $\begin{array}{l}\Phi \\
(\%)\end{array}$ & $\begin{array}{l}\tau \\
(\mathrm{ns})\end{array}$ & $\begin{array}{l}k_{\mathrm{rad}} \\
\left(\times 10^{7} \mathrm{~s}^{-1}\right)\end{array}$ & $\begin{array}{l}k_{\text {nrad }}\left(\times 10^{7}\right. \\
\left.\mathrm{s}^{-1}\right)\end{array}$ \\
\hline initiator & 17.4 & 3.3 & 5.3 & 25.0 & 17.2 & 3.3 & 5.2 & 25.1 \\
\hline PCL4k-TPE & 7.2 & 2.3 & 3.1 & 40.3 & 5.1 & 1.9 & 2.7 & 49.9 \\
\hline PCL8k-TPE & 5.7 & 2.0 & 2.9 & 47.2 & 3.4 & 1.7 & 2 & 56.8 \\
\hline PCL12k-TPE & 5.4 & 1.7 & 3.2 & 55.6 & 3.1 & 1.5 & 2.1 & 64.6 \\
\hline
\end{tabular}

Notes: measured at $25{ }^{\circ} \mathrm{C}$. For the PCL-TPE after melting, the samples were melted at $80{ }^{\circ} \mathrm{C}$ for $5 \mathrm{~min}$, and then temperature was restored to $25^{\circ} \mathrm{C}$. For initiator after melting, the initiator was melting at $100^{\circ} \mathrm{C}$ for $5 \mathrm{~min}$, and then restored to $25^{\circ} \mathrm{C}$. 9 


\section{Crystallization and melting behaviors of PCL-TPE.}

PCL12K-TPE showed a distinct exothermic peak at $32{ }^{\circ} \mathrm{C}$ in cooling scan, revealing crystallization of PCL. A sharp endothermic peak at $52.5{ }^{\circ} \mathrm{C}$ was observed in the subsequent heating scan, assigned to melting of PCL crystals in heating scan (Figure S8). Similar to PCL12k-TPE, PCL-TPEs with lower molecular weights (PCL8k-TPE and PCL4k-TPE) were also crystallizable, as expected.
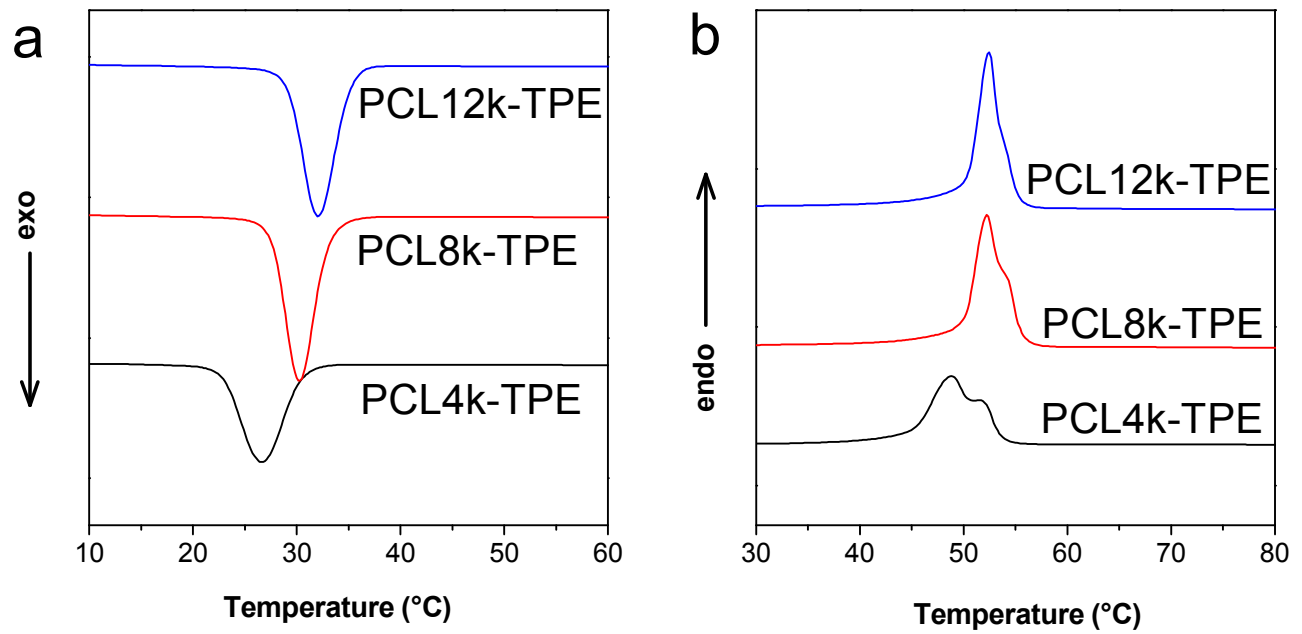

Figure S8. DSC traces of PCL-TPE (a) in cooling scan and (b) in heating scan. Heating and cooling rates were $10^{\circ} \mathrm{C} / \mathrm{min}$. 
Table S3. Crystallization Temperature, Melting Temperature, Fusion Enthalpy, the Degree of Crystallinity, Lamellar Thickness and Folding Number of PCL-TPE.

\begin{tabular}{|c|c|c|c|c|c|c|c|}
\hline Sample & $\begin{array}{l}\text { rate } \\
\left({ }^{\circ} \mathrm{C} / \mathrm{min}\right)\end{array}$ & $\begin{array}{l}T_{\text {onset }} \\
\left({ }^{\circ} \mathrm{C}\right)\end{array}$ & $T_{\mathrm{p}}\left({ }^{\circ} \mathrm{C}\right)$ & $\begin{array}{l}{ }^{\mathrm{a}} \Delta H \\
(\mathrm{~J} / \mathrm{g})\end{array}$ & ${ }^{\mathrm{b}} X_{\mathrm{c}}(\%)$ & $\begin{array}{l}{ }^{\mathrm{c}} L \\
\quad(\mathrm{~nm})\end{array}$ & ${ }^{\mathrm{d}} n$ \\
\hline \multirow[t]{2}{*}{ PCL4k-TPE } & 10 & 45.2 & $48.8 / 51.9$ & 63.2 & 48.2 & $7.3 / 8.7$ & 2 \\
\hline & -10 & 31.0 & 26.6 & 62.5 & - & & \\
\hline \multirow[t]{2}{*}{ PCL8k-TPE } & 10 & 48.3 & $52.2 / 54.1$ & 77.8 & 56.8 & $8.9 / 10.1$ & 5 \\
\hline & -10 & 33.5 & 30.3 & 76.7 & - & & \\
\hline \multirow[t]{2}{*}{ PCL12k-TPE } & 10 & 49.2 & $52.5 / 53.9$ & 77.2 & 55.6 & $9.1 / 10.0$ & 8 \\
\hline & -10 & 35.2 & 32.0 & 76.9 & - & & \\
\hline
\end{tabular}

${ }^{\mathrm{a}} \Delta H$ of ideal PCL crystal is $142.9 \mathrm{~J} / \mathrm{g} .{ }^{\mathrm{b}}$ The degree of crystallinity of PCL-TPE $\left(X_{\mathrm{c}}\right)$ was calculated using $X_{\mathrm{c}}=\Delta H /[142.9 \times(1-w)](w$ denoted the weight fraction of TPE in PCL-TPE, Table S1). ${ }^{\mathrm{c}} L$ denoted lamellar thickness calculated according to Gibbs-Thompson equation. ${ }^{\mathrm{d}} n$ denoted folding number of PCL-TPE.

\section{Lamellar thickness of PCL-TPE}

Thickness of PCL crystals $(l)$ in PCL-TPE was calculated using Gibbs-Thompson equation:

$$
T_{m}=T_{m}^{0}\left(1-\frac{2 \sigma_{e}}{l \Delta H_{f}}\right)
$$

where $T_{\mathrm{m}}{ }^{0}$ is equilibrium melting temperature with a value of $342.2 \mathrm{~K}$ for PCL single crystals, ${ }^{2} T_{\mathrm{m}}$ is experimental melting temperature, $\sigma_{\mathrm{e}}$ is the basal surface free energy with a value of $4.32 \times 10^{-2} \mathrm{~J} / \mathrm{m}^{2}$ for PCL crystals, and $\Delta H_{\mathrm{f}}$ is the heat of fusion per unit 
volume of the crystal with a value of $1.88 \times 10^{8} \mathrm{~J} / \mathrm{m}^{3}$ for PCL crystals. Lamellar thickness of PCL-TPE was summarized in Table S3.

\section{Folding number of PCL in PCL-TPE crystals.}

The length of fully extended polycaprolactone chains was estimated to be $0.86 \cdot \mathrm{DP} \mathrm{nm}$ using ChemDraw 7.5 (DP was the number of repeating units of PCL-TPE).

The folding number of PCL in PCL-TPE was determined to be the integer of $0.86 \cdot \mathrm{DP} / l-1$, where $l$ was the thickness of PCL-TPE lamellae. The folding number of PCL in PCL-TPE was tabulated in Table S3.

\section{Calculation of grafting density of TPE on PCL-TPE crystals.}

Grafting density $(G)$ of TPE on PCL-TPE crystals was calculated based on the lamellar model in Scheme 1 using the following formula:

$G=N_{\mathrm{A}} \cdot W \cdot d \cdot L / 2 / M_{\mathrm{TPE}}$

where $N_{\mathrm{A}}$ is Avogadro's number, $W$ is weight fraction of TPE moieties of PCL-TPE, $L$ is the thickness of lamellar crystals of PCL-TPE. $d$ is density of PCL-TPE, estimated using $d=W \cdot d_{\mathrm{TPE}}+(1-W) \cdot d_{\mathrm{PCL}} \quad\left(d_{\mathrm{PCL}} \quad\right.$ is density of $\mathrm{PCL}, \quad 1.145 \mathrm{~g} / \mathrm{cm}^{3}$, http://en.wikipedia.org/wiki/Polycaprolactone; $d_{\mathrm{TPE}}$ is density of TPE, $1.088 \mathrm{~g} / \mathrm{cm}^{3}$, http://en.wikipedia.org/wiki/Tetraphenylethylene). Grafting density of TPE in PCL-TPE was summarized in Table S3. 
Table S4. Grafting Density $(G)$ and Coverage Ratio $(C)$ of TPE on PCL-TPE Crystal Surface before and after Melting.

\begin{tabular}{lllll}
\hline Sample & \multicolumn{2}{c}{ before melting } & \multicolumn{2}{c}{ after melting } \\
\cline { 2 - 5 } & $G\left(10^{17} \mathrm{~m}^{-2}\right)$ & $C(\%)$ & $G\left(10^{17} \mathrm{~m}^{-2}\right)$ & $C(\%)$ \\
\hline PCL4k-TPE & 9.1 & 70 & 6.2 & 48 \\
PCL8k-TPE & 5.6 & 44 & 3.9 & 30 \\
PCL12k-TPE & 4.0 & 31 & 2.6 & 21 \\
\hline
\end{tabular}

With decreasing molecular weight of PCL-TPE, TPE coverage ratio on PCL-TPE crystal surface increased from $31 \%$ to $70 \%$. After melting, TPE coverage ratio decreased compared to that before melting. This demonstrated that PCL-TPE after melting possessed less perfect crystalline structures than those before melting.

\section{Calculation of coverage ratio of TPE on PCL-TPE crystal surface.}

Coverage ratio $(C)$ of TPE on PCL-TPE lamellae can be calculated by using $C=G \cdot A$

where $A$ is cross-sectional area of TPE, approximately being $0.91 \times 0.85 \mathrm{~nm}^{2}=7.74 \times$ $10^{-19} \mathrm{~m}^{2}$. The coverage ratio $(C)$ of TPE on PCL-TPE crystal surface was summarized in Table S4. 
Scheme S2. Ball-Stick Modeling (a) and Space Filling Modeling (b) of TPE Showing Dimensions of $0.91 \times 0.85 \mathrm{~nm}^{2}$. Modeling was carried out using Chemoffice software (ChemDraw 7.5).
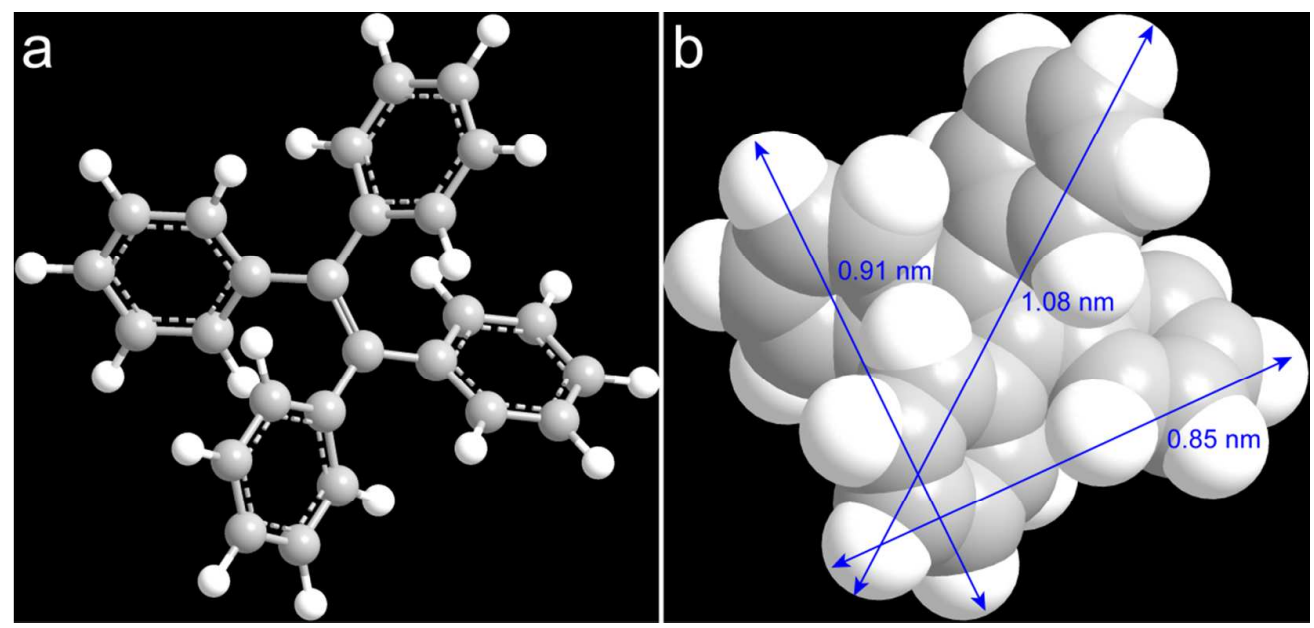

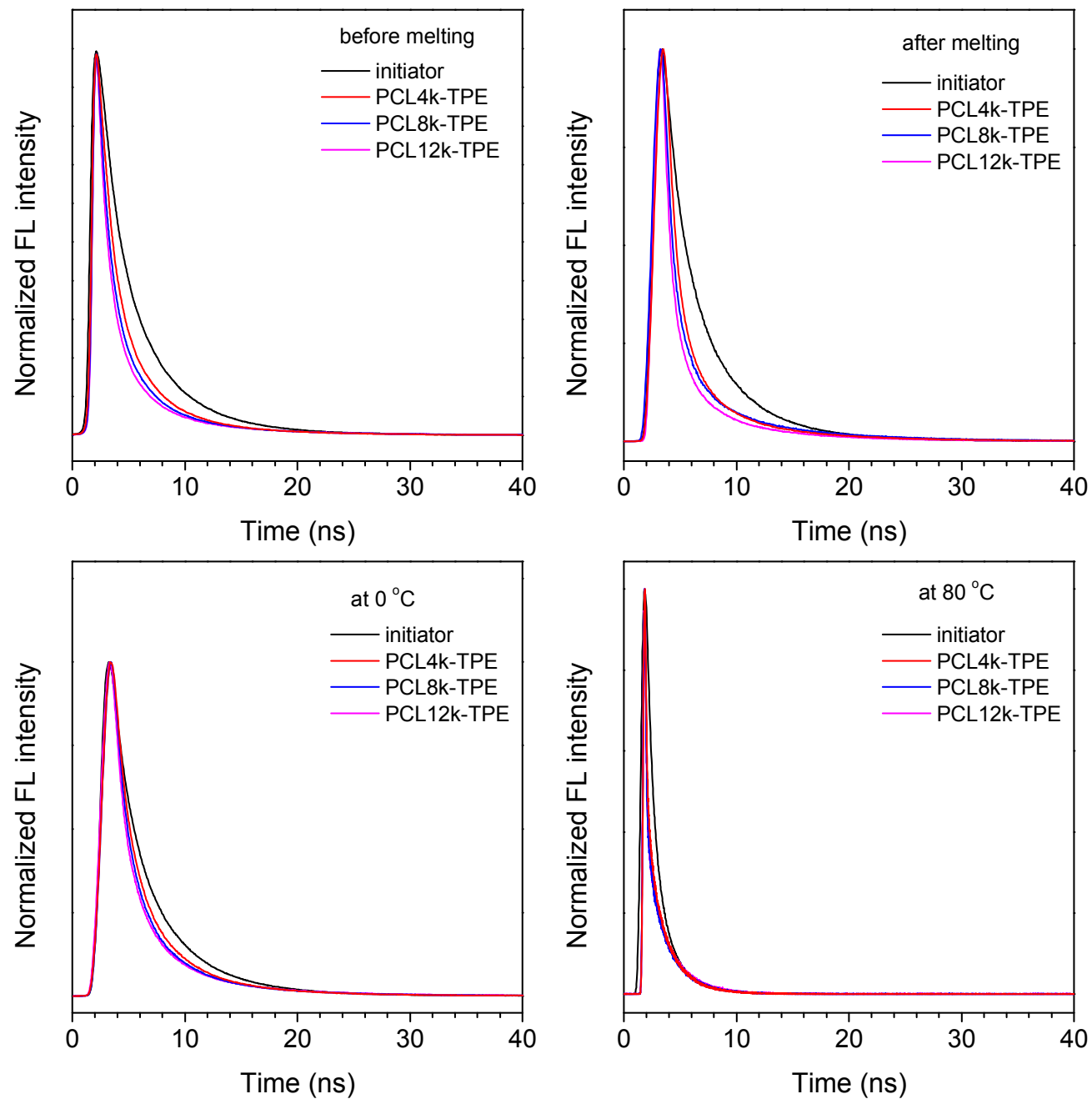

Figure S9. Time-resolved fluorescence spectra of PCL-TPE and the initiator (compound 1, Scheme S1) at 25, 0 and $80{ }^{\circ} \mathrm{C}$.

Table S5. Lifetime of PCL-TPE and the Initiator at $0{ }^{\circ} \mathrm{C}$ and $80{ }^{\circ} \mathrm{C}$.

\begin{tabular}{lll}
\hline Sample & \multicolumn{2}{c}{$\tau(\mathrm{ns})$} \\
\cline { 2 - 3 } & $0{ }^{\circ} \mathrm{C}$ & $80{ }^{\circ} \mathrm{C}$ \\
\hline initiator & 3.46 & 1.08 \\
PCL4k-TPE & 2.71 & 1.04 \\
PCL8k-TPE & 2.45 & 0.99 \\
PCL12k-TPE & 2.36 & 1.02 \\
\hline
\end{tabular}




\section{Structural evolution of PCL-TPE in heating and cooling scans.}

The crystallinity $\left(X_{\mathrm{c}}\right)$ of PCL and the crystallite size perpendicular to (hkl) plane $\left(L_{\mathrm{hkl}}\right)$ were estimated using MDI Jade 5.0 software.
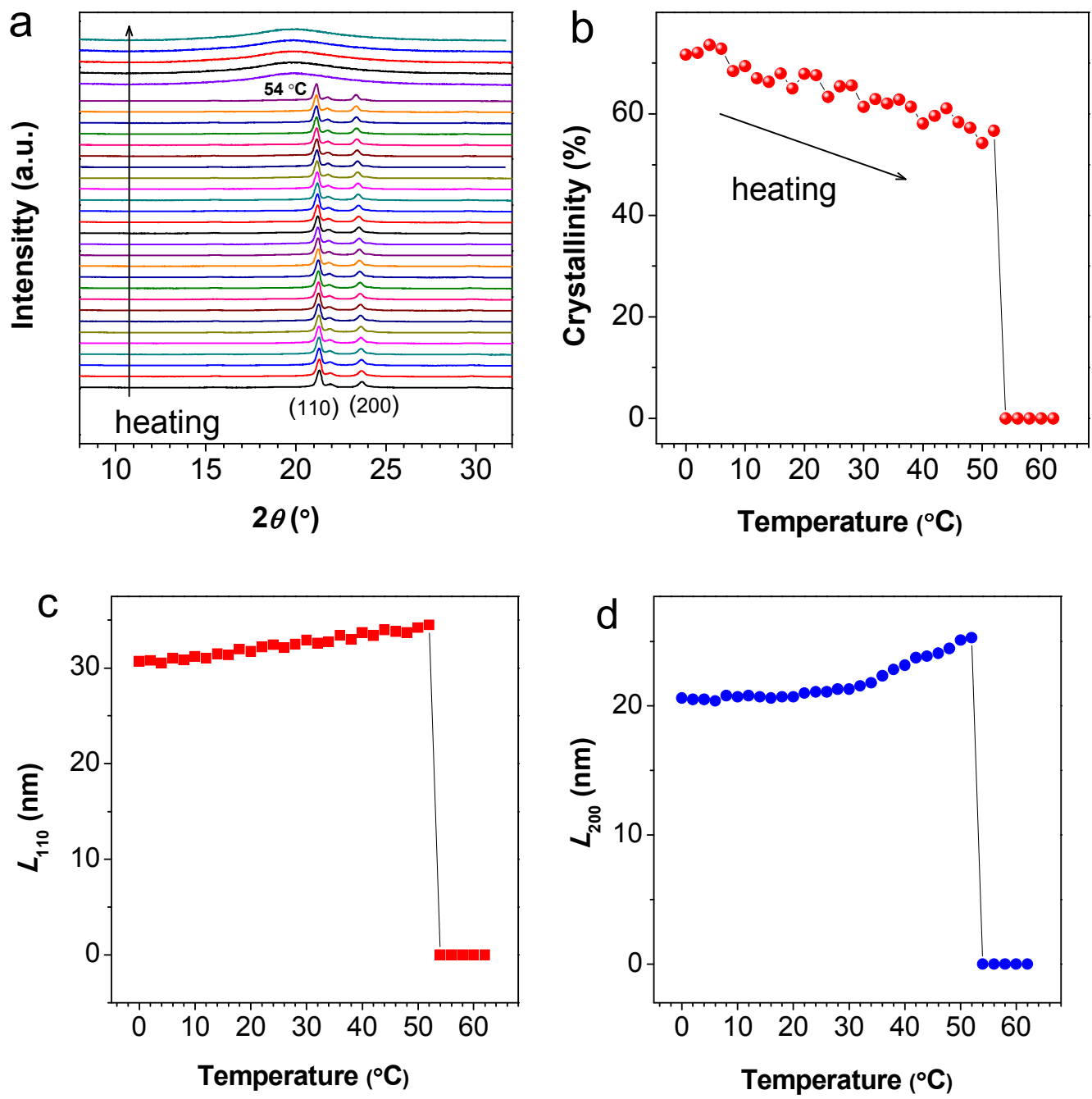

Figure S10. Evolution of crystalline structures of PCL-TPE in heating scan. (a) XRD spectra of PCL12k-TPE at various temperatures. (b) Variation of crystallinity of PCL12k-TPE against temperature in heating scan. (c) $L_{110}$ and (d) $L_{200}$ as a function of temperature in heating scan. 

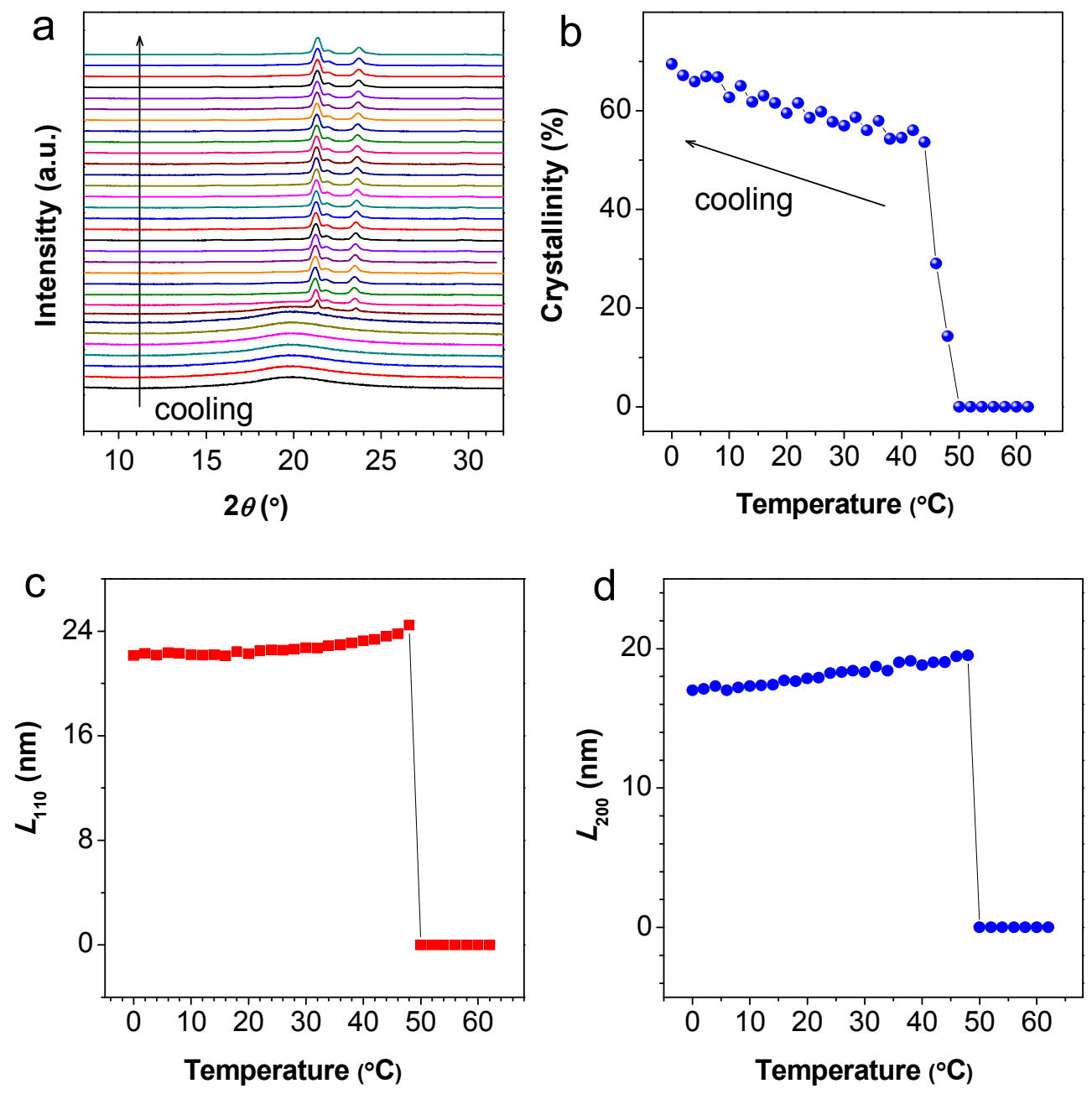

Figure S11. Evolution of crystalline structures of PCL-TPE in cooling scan. (a) XRD spectra of PCL12k-TPE at various temperatures. (b) Variation of crystallinity of PCL12k-TPE against temperature in cooling scan. (c) $L_{110}$ and (d) $L_{200}$ as a function of temperature in cooling scan. 


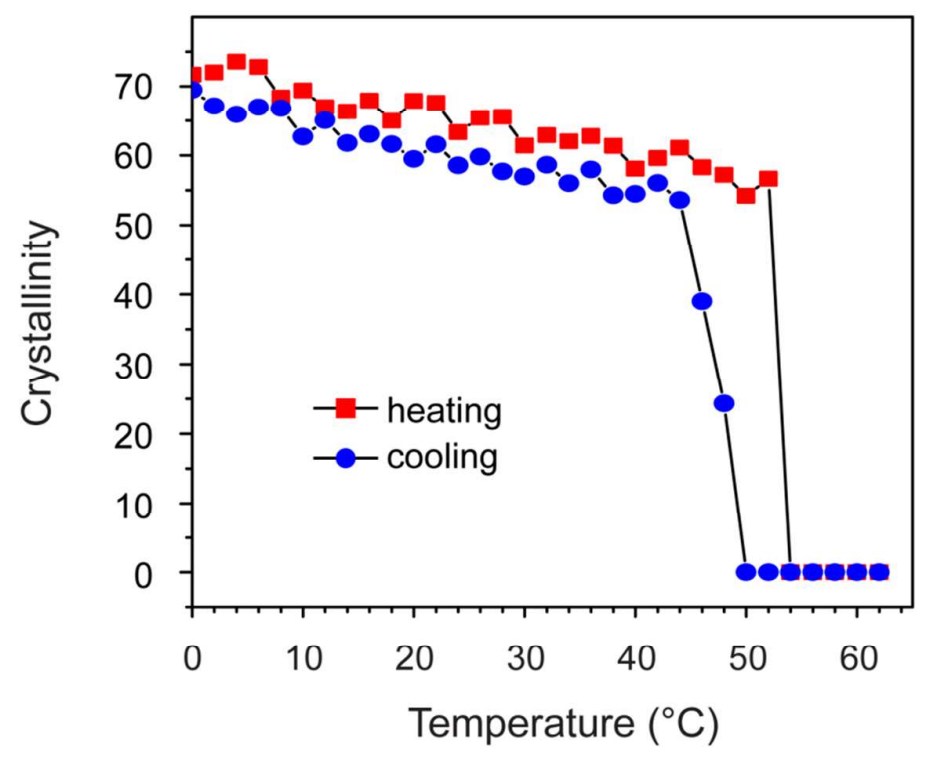

Figure S12. Crystallinity of PCL12k-TPE at various temperatures in heating and cooling scans.

Table S6. Melting Temperature, Fusion Enthalpy and the Degree of Crystallinity of PCL-TPE before Melting.

\begin{tabular}{lllllll}
\hline Sample & $\begin{array}{l}T_{\text {onset }} \\
\left({ }^{\circ} \mathrm{C}\right)\end{array}$ & $T_{\mathrm{p}}\left({ }^{\mathrm{o}} \mathrm{C}\right)$ & ${ }^{\mathrm{a}} \Delta H$ & ${ }^{\mathrm{b}} X_{\mathrm{c}}(\%)$ & ${ }^{\mathrm{c}} L$ & ${ }^{\mathrm{d}} n$ \\
\hline PCL4k-TPE & 48.6 & 54.9 & 99.9 & 56.2 & 10.7 & 1 \\
PCL8k-TPE & 52.5 & 57.2 & 102.9 & 65.2 & 12.9 & 3 \\
PCL12k-TPE & 53.4 & 58.0 & 100.5 & 62.4 & 13.8 & 5 \\
\hline
\end{tabular}

${ }^{\mathrm{a}} \Delta H$ of ideal PCL crystal is $142.9 \mathrm{~J} / \mathrm{g} .{ }^{\mathrm{b}}$ The degree of crystallinity of PCL-TPE $\left(X_{\mathrm{c}}\right)$ was calculated using $X_{\mathrm{c}}=\Delta H /[142.9 \times(1-w)]$ ( $w$ denoted the weight fraction of TPE in PCL-TPE, Table S1). ${ }^{\mathrm{c}} L$ denoted lamellar thickness calculated according to Gibbs-Thompson equation. ${ }^{\mathrm{d}} n$ denoted folding number of PCL-TPE. 


\section{Retrieving thermal history.}
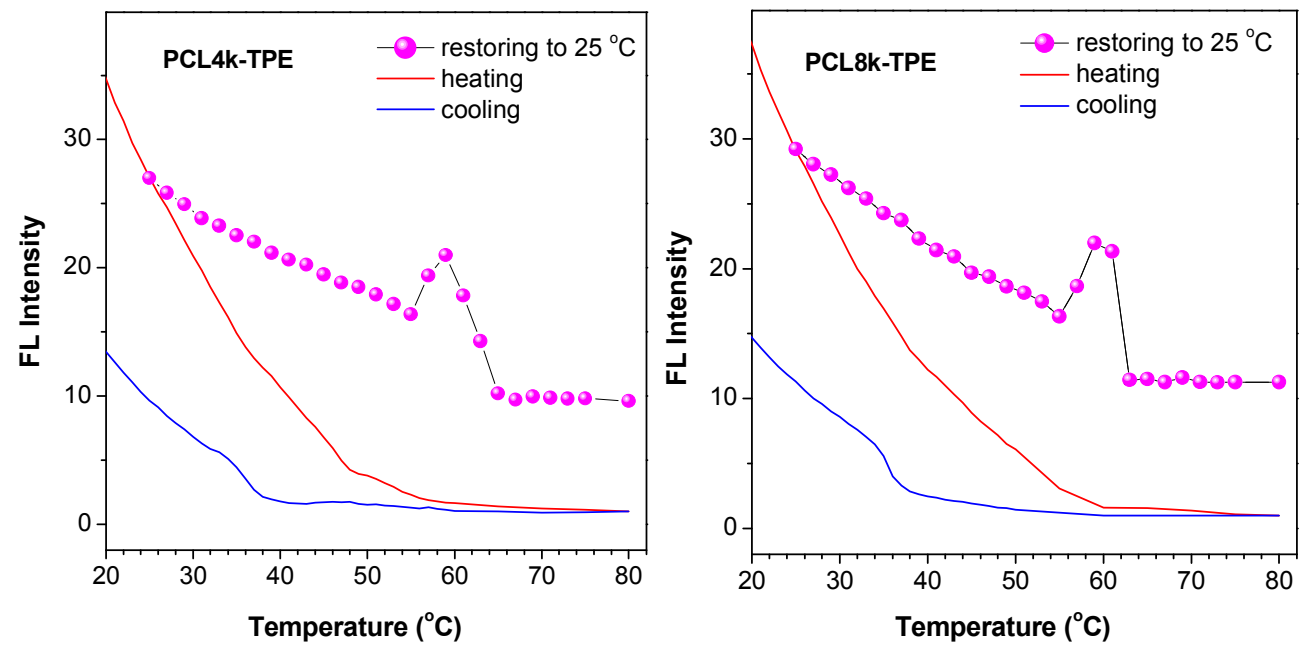

Figure S13. Retrieving thermal history above $25{ }^{\circ} \mathrm{C}$ using PCL4k-TPE and PCL8k-TPE.

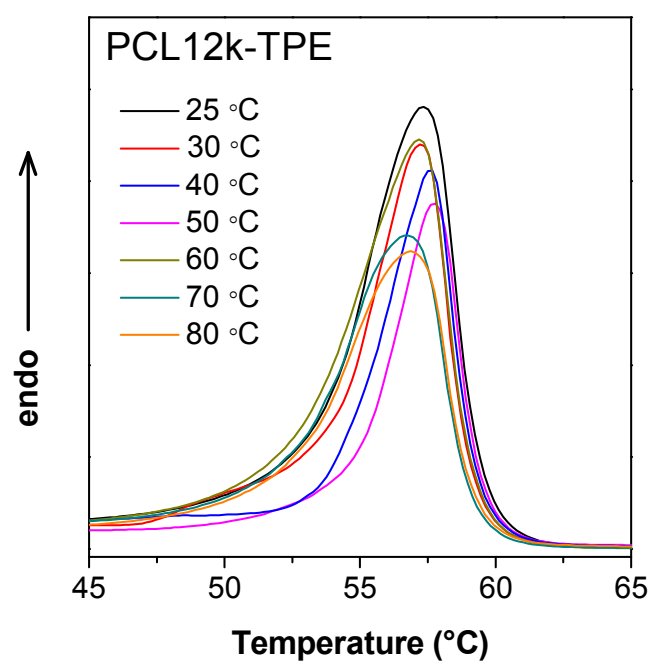

Figure S14. DSC curves of PCL12k-TPE ever heated to various historical temperatures. With increasing historical temperature from $25,30,40$ and $50{ }^{\circ} \mathrm{C}$, the endothermic peak became weak and narrow gradually, likely due to melting the thin crystalline lamellae. An increase in endotherm was observed at $60{ }^{\circ} \mathrm{C}$. Further increasing historical temperature to $80{ }^{\circ} \mathrm{C}$, the endothermic peak became weak and 
broad, and shifted to low temperature.

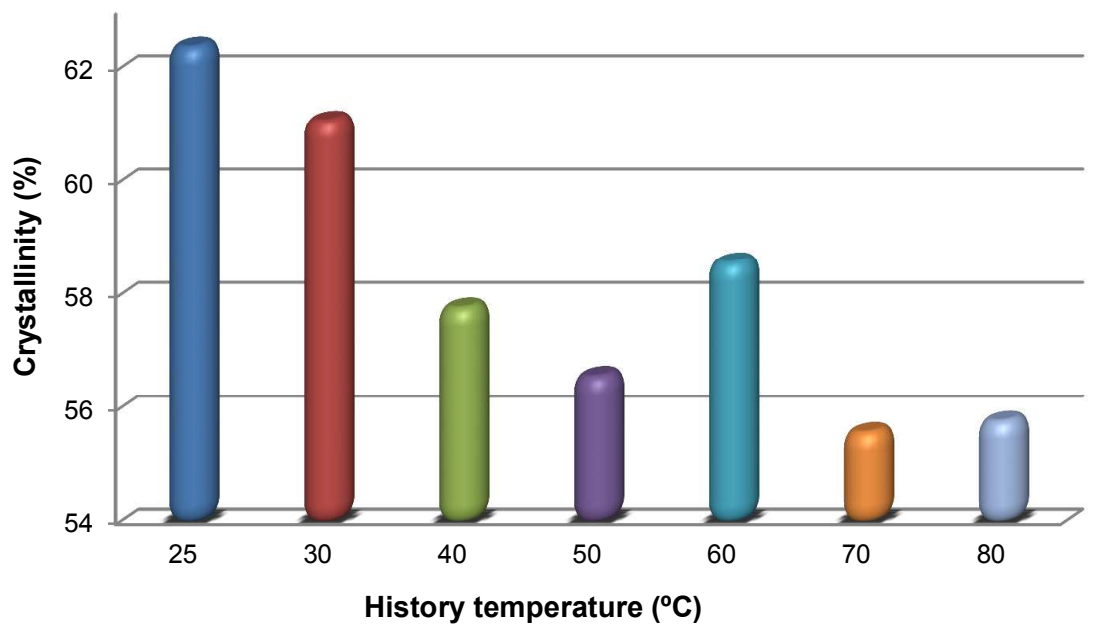

Figure S15. Crystallinity of PCL-TPE as a function of history temperature.
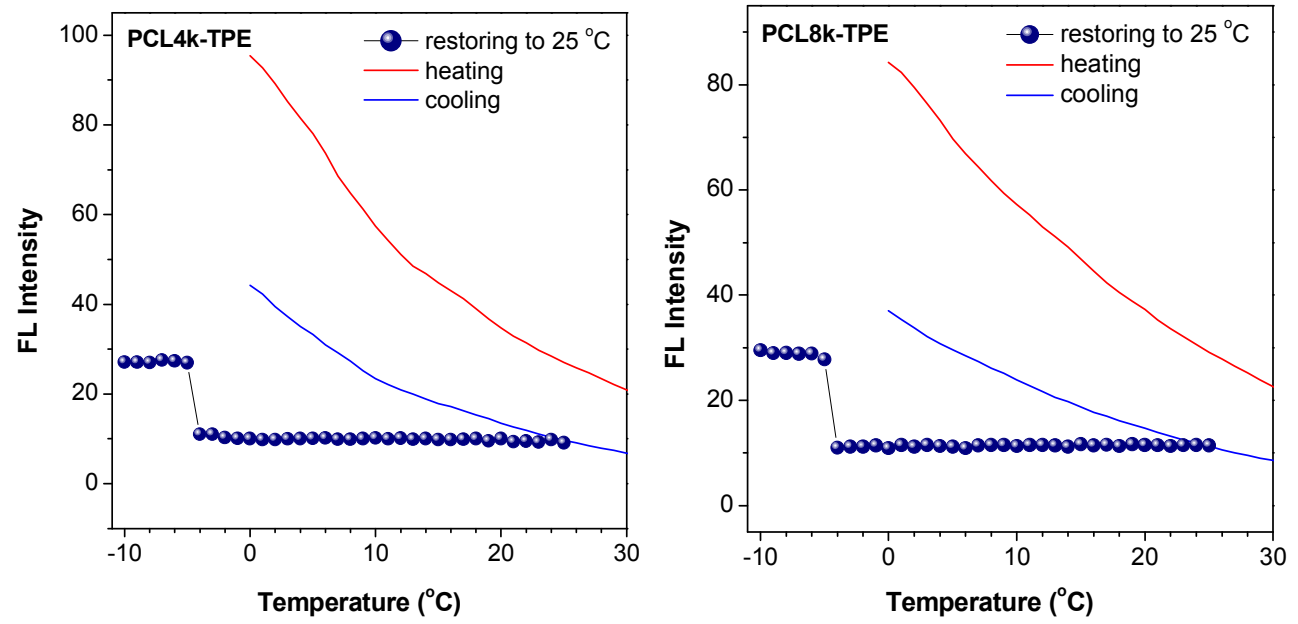

Figure S16. Retrieving thermal history below $25{ }^{\circ} \mathrm{C}$ using PCL4k-TPE and PCL8k-TPE.

\section{Supplementary movies.}

We provide a movie as supplementary material: Fluorescence of PCL12k-TPE was switched by cooling at $0{ }^{\circ} \mathrm{C}$ and heating at $80{ }^{\circ} \mathrm{C}$, respectively. The fluorescence 20 
switching was reversible over 20 cycles by repeatedly applying cooling and heating. Movie.avi | Fluorescence switching of PCL12k-TPE by repeatedly cooling at $0{ }^{\circ} \mathrm{C}$ and heating at $80^{\circ} \mathrm{C}$, respectively.

(1) (a) Bao, S. P.; Wu, Q. H.; Qin, W.; Yu, Q. L.; Wang, J.; Liang, G. D.; Tang, B. Z. Polym. Chem. 2015, 6, 3537-3542; (b) Liang, G. D.; Lam, J. W. Y.; Qin, W.; Li, J.; Xie, N.; Tang, B. Z. Chem. Commun. 2014, 50, 1725-1727.

(2) Sasaki, T. J. Therm. Anal. 2013, 111, 717-724. 